\title{
Mini-Review in Bone Marrow Aspirate Concentrate
}

\author{
Hazim Abdul Rahman Alhiti ${ }^{1 *}$, Sarah Tareq Abdul_Azeez ${ }^{2}$ and Ahmad Mansour Hamad ${ }^{3}$ \\ ${ }^{1}$ Head of emergency department, Higher Institute of Health, Al Anbar Directorate of Health, Iraq \\ ${ }^{2}$ Specialist in Rheumatology and rehabilitation unit, Internal medicine department, Ramadi Teaching Hospital M.B.CH.B. MSC, \\ Rheumatology and Rehabilitations, Baghdad University, Iraq
}

${ }^{3}$ Manager of Al Zahrawy Center for Stem Cells in Baghdad, Iraq

*Corresponding author: Hazim Abdul Rahman Alhiti, General Surgeon Specialist M.D, Al-Ramadi Teaching Hospital, general surgeon specialist, Chief of Breast Clinic (Hit General Hospital), Chief of Cancer Clinic (Hit General Hospital), Academic lecturer (Electronic learning)- Tikrit University, Academic lecturer in Higher Institute of Health, Al Anbar Directorate of Health, Head of emergency department, Higher Institute of Health, Al Anbar Directorate of Health, Iraq

ARTICLE INFO

Received: 櫘 December 06, 2021

Published: 慧 December 13, 2021

Citation: Hazim Abdul Rahman Alhiti, Sarah Tareq Abdul_Azeez, Ahmad Mansour Hamad. Mini-Review in Bone Marrow Aspirate Concentrate. Biomed J Sci \& Tech Res 40(3)-2021. BJSTR. MS.ID.006463.

\section{ABSTRACT}

Introduction: Bone Marrow Aspirate Concentrate (BMAC) is an innovative regenerative method.

Aim: To reveal the importance of the BMAC in curing man's diseases.

Methods: It is a mini-review report concerning the BMAC by searching in google scholar in the last five years.

Results: BMAC procedure is harmless, comfortable, safe, plus high satisfaction technique. Furthermore, BMAC had lower patient mortality plus morbidity.

Conclusion: BMAC is a good choice in curing or alleviating man's difficult-to-treat diseases.

Keywords: Bone Marrow Aspirate Concentrate; BMAC; Regenerative; Procedure

\section{Introduction}

A Bone Marrow Aspirate Concentrate procedure (BMAC) is an innovative regenerative method implemented in medical practice since the early nineteenth century as a simple medical relief that grew steadily through good experiences and training. Consequently, these undifferentiated stem cells create diverse kinds of differentiated cells. [1]. The BMAC procedure is an uncomplicated technique that runs on various diseases not cured by traditional remedies or pathologies that need principal medicine. Therefore, in the BMAC method, the operator inserted the BMAC in the hurt tissue to form subsequent physiological chains in the involved tissue. Consequently, the BMAC exhibited the capability to assist the diseased tissue microstructure for tissue reconstruction over time. [2]. The earlier BMAC testers attempted victorious trials of the BMAC method in animals and later in humans with excellent outcomes. Furthermore, the experimenters illuminated the growing pertinence of the BMAC in many disorders and unmanaged conditions [3]. BMAC method included catching a small amount of the participant bone marrow from the (anterior or posterior part of the pelvis) by local an aesthesia as an outpatient procedure. The operator transfers this part of bone marrow to a specialized laboratory in an aseptic way.

Hence, the laboratory operator collects the stem cells by an activation device like "Adi-Stem, AdiLight-2 Photo device" and guards these stem cells to reinsert them into the same patient blood or the diseased tissue for the cure [4]. Consequently, the doctor proffered the sufferer a painkiller and advised of bed rest for a week. After that, the specialist will follow the patients with education and rehabilitation after the BMAC shot, but if the patient 
did not benefit from the first shot of BMAC, the physician gave a second injection after three weeks [5]. BMAC accommodates immature stem cells plus growth factors, which gave more influence than the "autologous platelet-rich plasma". Hence, this plasma holds the growth factors only. Afterward, this essential contrast offers the BMAC effectiveness in tissue regeneration plus emblematic symptom amelioration [6]. In 2020, the Food and Drug Administration (FDA) in the USA approved "blood-forming stem cells" or "hematopoietic progenitor cells" from umbilical cord blood, but in 2021 the USA approved other types of stem cells. Nevertheless, some principal academic hospitals in the USA and developed nations with excellent results. Further, Native Stem Cell Hospitals practiced BMAC treatment following 2014. Moreover, in 2020 the Food and Drug Administration acquired specific guidelines [7].

\section{Uses of BMAC}

\section{A. Musculoskeletal Conditions}

1. Accelerate Fracture Healing

2. Cure Non-United Fractures

3. Cure Early Osteoarthritis

4. Reliving Osteoarthritic Pain

5. Cure Early Osteonecrosis

6. Enhance Cartilage Repair and Capacity

7. Cure Osteochondritis

8. Delay Arthritic Progress

9. Cure Ligament Injuries

10. Cure Disc Disease

11. Heal Meniscal Injuries

B. Skin

1. Heals Chronic Skin Wounds

2. Treat Chronic Skin Ulcers

3. Treat Difficult Burns

C. Nerves

1. Cure Spinal Cord Injuries

2. Heals

3. Cerebral palsy

D. Wounds

1. Heal chronic wounds

2. Repairing muscle loss
3. Improve muscle healing

E. Diabetes

1. Cure type 1 diabetes mellitus

2. Lowering blood sugar in type 2 diabetes mellitus

3. Repair diabetic foot

F. Ischemia

1. Congestive Heart Failure

2. Heart Failure

3. Critical limb ischemia

G. Eye Diseases

1. Usher syndrome

2. Serpiginous Choroidopathy

3. Dominant Optic Atrophy

H. Ear Diseases

1. Usher syndrome

2. Ear Cartilage loss

3. Cochlear disease

I. Brain

1. Autism

2. Stroke

3. Traumatic Brain

\section{Complications of BMAC}

A. Most of those complexities are minor and settle spontaneously.

1. Pain in situ

2. Simple discomfort

3. Hematoma

4. Numbness

5. Need repeated applications

\section{Limitations of BMAC Procedure}

1. Not Licensed in Some Countries

2. Expensive

3. Not In Health Insurance List

4. Repeated Injections

5. Need Special Laboratory Tools 


\section{Results}

BMAC procedure is harmless, comfortable, safe, plus high satisfaction technique. Furthermore, BMAC had lower patient mortality plus morbidity.

\section{Conclusion}

BMAC is a good choice in curing or alleviating man's difficultto-treat diseases.

\section{References}

1. Snow M (2018) Bone Marrow Aspirate Concentrate and Expanded Stem Cell Applications in Orthopaedics. Bentham Science Publishers.

2. Law L (2019) Scientific Basis for Stem Cell Therapy. In: Deer T Deer's Treatment of Pain. Springer, Cham.

ISSN: 2574-1241

DOI: 10.26717/BJSTR.2021.40.006463

Hazim Abdul Rahman Alhiti. Biomed J Sci \& Tech Res

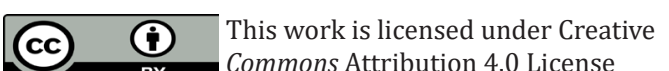

Submission Link: https://biomedres.us/submit-manuscript.php
3. Von Rickenbach K (2021) Orthobiologics. In: Schoenfeld A Principles of Orthopedic Practice for Primary Care Providers. Springer, Cham.

4. Chahla J, Sandeep Mannava, Mark E Cinque, Andrew G Geeslin, David Codina, et al. (2017) Bone Marrow Aspirate Concentrate Harvesting and Processing Technique. Arthro Tech 6(2): 441-445.

5. Ernat J (2021) A Review of Bone Marrow Aspirate Concentrate and Its Use in Primary Osteoarthritis of the Knee J Orthop Sports Med, p. 62-74.

6. Lana J, Lucas Furtado da Fonseca, Rafael da Rocha Macedo, Tomas Mosaner, William Murrell, et al. (2021) Platelet-rich plasma vs bone marrow aspirate concentrate: An overview of mechanisms of action and orthobiologic synergistic effects. World J Stem Cells 13(2): 155-167.

7. Kubrova E, D Souza, Ryan S, Wang Qian, Andre J, et al. (2020) Injectable Biologics. AJPMR 99(10): 950-960.

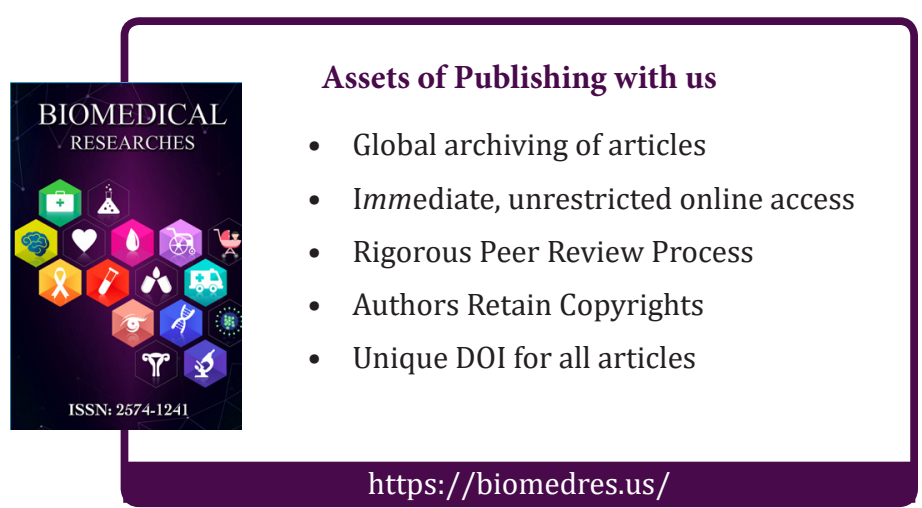

